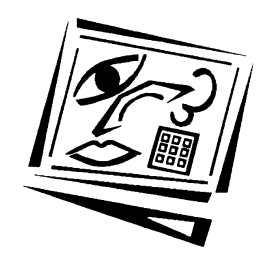

\title{
Learner perceptions and recall of small group discussions within 2D and 3D collaborative environments
}

\author{
Steve Downey \\ Valdosta State University
}

Jill Mohler, Joan Morris and Rene Sanchez

University of South Florida

\begin{abstract}
Online learning critically relies upon good communication between engaged parties in order to convey ideas, meanings, and values. Emerging technologies in collaborative virtual environments are providing new affordances in establishing greater online presence and, in turn, greater abilities to communicate and learn. This study examines how learners perceive, follow, and recall information presented in discussions in both a 2D and a 3D collaborative environment, Elluminate (now known as Blackboard Collaborate) and Second Life respectively. This exploratory study shows that learners observing discussions in Second Life have a tendency to better organise ideas, better identify who said what, and better recall what information was said throughout the discussion, than with similar discussions in Elluminate. On average, participants in this small scale study were able to follow and recall conversations in Second Life 10-13\% better than the discussions in Elluminate. While findings produced positive trends towards Second Life, additional testing is required as the scale $(\mathrm{n}=42)$ was small and the frequencies of statistical results in excess of .05 were limited. Still, collectively they do point towards valuable insights for online educators in how they choose to deliver content, conduct synchronous class discussions, and communicate with their students.
\end{abstract}

\section{Introduction}

Teaching is essentially a matter of facilitating learning, and where that learning depends on communication between the teacher and the learner, the same principles apply as in any successful conversation. The aim must be the collaborative construction of meaning, with negotiation to ensure that meanings are mutually understood. (Wells, 1986, p. 101)

As much as traditional, face to face learning relies upon good communication between the instructor and the students, for students engaged in online learning the communication process is critical (Ott, 2001; Wang, 2008). "Online learning isn't about computers anymore; it is about communication, and successful learning depends on communication" (Ott, 2001). Without the ability to rely on non-verbal/visual cues to aid the communication process through mainstream online instructional media (e.g., web pages, emails, discussion board postings, etc.), students and instructors engaged in web-based instruction must become technically savvy in order to filter out noise, understand context, and infer meaning from the communicator's original message.

Good online communication, i.e., communication in which quality educational content is exchanged between teacher and student, is a critical component in the online 
learning process. In terms of student-teacher exchanges, these multi-dimensional interactions contain several communication-based factors such as quality of feedback (i.e., accurate and timely) and intellectual depth of dialogue (Berge, 2002; Gunawardena, 1995; Swan, 2001). As Palloff and Pratt (2003) wrote, "what the virtual student wants and needs is very clear: communication and feedback, interactivity and a sense of community, and adequate direction and empowerment to carry out the tasks required for the course" (pp. 129-130). The challenge for educators is learning to utilise the affordances of the technologies they employ and maximise their potential for communication and student-teacher collaboration. Garrison and Anderson (2003) stated "educators have not understood and capitalized on the blend of symbol systems, such as multimedia, text-based communication systems that create new modes of expression and communication" (p. 4).

Similar arguments are made relating to student-student communication. Students want peer interaction, social presence, and environments supporting highly collaborative tools (Muirhead, 1999; Northrup, 2009; Palloff \& Pratt, 2003; Su, Bonk, Magjuka, Liu \& Lee, 2005). The notion of social presence, in particular, is directly related to this study as it impacts how learners project themselves into the learning environment and present themselves to each other (Dede, 2005; International Society for Presence Research, 2000). As such, it directly affects the degree to which learners can utilise established communication approaches (see Figure 1), without having to adapt their ingrained behaviours and/or learn new communication skills. The more easily learners can establish an online presence in their learning environment, the more easily they should be able to communicate, collaborate, and learn.

The research in this exploratory study focused on the affordances (i.e., visual cues) that contribute to the communication process facilitating learning. In particular, researchers studied how well learners in 2D (two-dimensional) and 3D (three-dimensional) collaborative environments were able to (a) follow the course of a discussion and (b) recall information from that discussion after a brief period of time had passed. The discussions, themselves, utilised affordances commonly employed in the 2D and 3D environments. By understanding how learners utilised the affordances associated with 2D and 3D environments in order to follow and comprehend the content of small group discussions, we can aid practitioners in establishing guidelines for conducting effective synchronous dialogues resulting in potentially stronger learning gains for their students.

\section{Interdependence between online learning, communication, and technology affordances}

For years computer-mediated communication and human-computer interaction research has sought to understand and describe the human experience when mediated by technology. Researchers continuously have sought to determine if and how new media influence the pattern of human interactions and communication (McQuail, 1994; Potter, 2004; Williams, 2010). In trying to make these determinations, researchers have examined various aspects of a strong but subtle interdependency between (i) online learning, (ii) communication, in the form of media literacy (Potter, 2004; Williams, 2010), (iii) technological affordances (Gibson, 1977; Norman, 1988), and (iv) each user's online presence (Minsky, 1980). As Figure 1 illustrates, online learning is facilitated through each of the three underlying factors (communication, technology, and presence). It is the visual affordances associated with two different technologies, 
Elluminate, (2D) and Second Life (3D), and their subsequent impact on communication and learning that are the focus of this study.

Note that Elluminate is now known by the product name Blackboard Collaborate (Dawson, 2011), but because Elluminate was the name at the time the study was conducted, this article uses the former name. It should also be noted that Elluminate and Second Life are only examples of these environments and should not be considered to be representative of all such environments.

The theoretical foundations underlying this study stem from Gibson's (1977) and Norman's (1988) work related to the Theory of Affordances and from Potter's (2004) Theory of Media Literacy. The interactions between these two theory bases as they relate to online learning are captured below in Figure 1. The following two sub-sections describe the theoretical underpinnings of the two theory bases as they contribute to the interactions illustrated in Figure 1 and impact the online learning process.

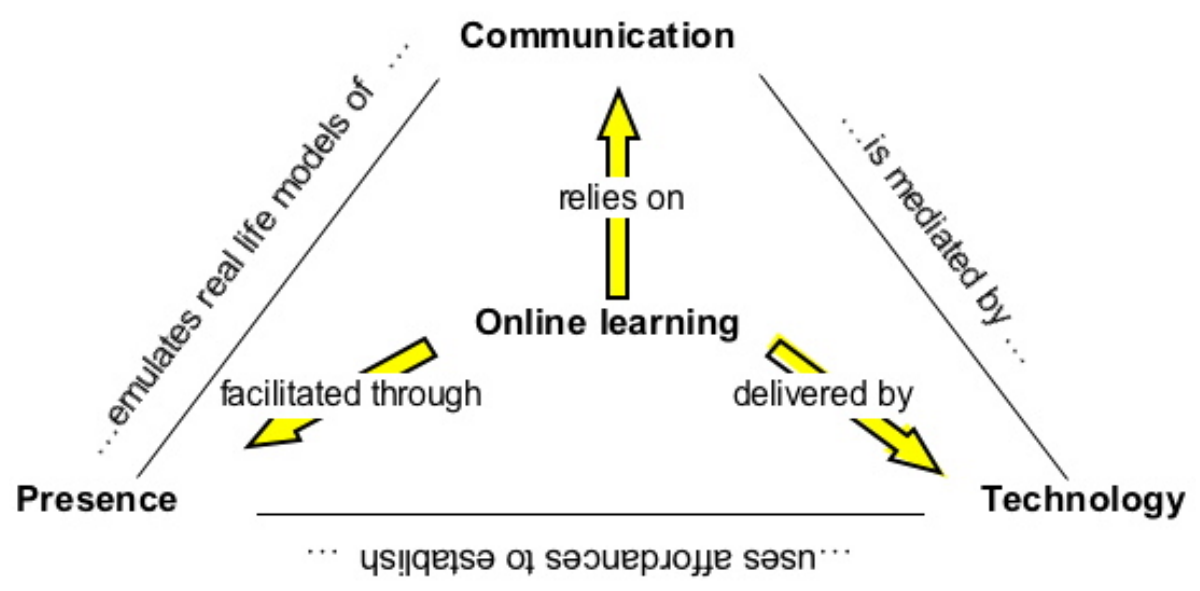

Figure 1: Interdependency of communication, technology affordances, and online learning

\section{Communication factors}

A variety of models have been used over the millennia to explain communication and, more specifically, the act of information processing. Aristotle put forth a simplistic model 2,300 years ago identifying three key elements in communication - speaker, subject, and listener (Croft, 2004; Lee, 1993; Narula, 2006). While his model was insightful for his era, Aristotle didn't clarify factors explaining why some listeners would perceive and interpret the meaning of the subject as intended by the speaker and others did not. More recently Harold Lasswell (1948) put forth a more discerning model encapsulated by asking the single question, "Who says what in which channel and with what effect?" (p. 117). By including "in which channel" Lasswell separates his model from previous models by noting that the delivery medium plays a key role in influencing the message received by the listeners. This concept later would be popularised by the pop culture phrase "The medium is the message" coined by Marshall McLuhan (1964). Shannon and Weaver (1949) extended Lasswell's model by recognising that distortions in the message can be caused by "noise" in the 
communication channel being used, and that some channels afforded better noise mitigation than did others. The selection of communication channels (i.e., online environments) based upon their affordances and ability to mitigate noise while reinforcing the message being transmitted is a key element in the study being presented.

In more recent research, Potter's (2004) Theory of Media Literacy breaks down how information perceived in selected communication channels can affect overall cognition. He wrote, "Perception precedes cognition. Perception is the act or process by which the organs of reception are stimulated by physical sensations, first becoming aware of them, then categorizing and codifying them" (Potter, 2004, p. 141). The act of categorising requires users to make decisions regarding what to filter-in and retain for further processing and filter-out as noise. This decision-making process is the connection between the communication/ information processing theory base and theory of affordances base. As users interact with an environment, whether 2D or 3D, they actively search for visual cues and information related to their cognitive activity (Potter, 2004). It is the affordances of an environment that affect a user's ability to perceive these cues and initiate the decision-making process to filter, categorise, and codify the information perceived (Gibson, 1977; Norman, 1988).

\section{Technological affordances and presence}

Gibson (1977) brought attention to the notion of affordances as he detailed how the combined properties of an object, be it a door, chair, or computer interface, endowed it with certain abilities to support actions desired by a user. He sought to demonstrate "that the variables of substances and layout combine to make affordances for animals and to demonstrate that the optical information for perceiving the variable combines to yield information" (Gibson, 1977, p. 67). Norman (1988) extended Gibson's work by taking into account an individual's prior experience related to the object being actively scanned for affordances and information. In doing so, Norman recognised that affordances vary with the environments being used; and a user's experiences and preferences likely would influence which affordances would be capitalised upon by him/her. In agreement with this premise, participants in this study were surveyed both for their preferences regarding technological affordances as well their preferences in messages presentation (i.e., learning styles - see Methods section).

Norman (1988) went on to define Principles of Design for Understandability and Usability, for objects intended for use by humans. The two primary principles are: (1) provide a good conceptual model; and (2) make things visible. A third, separate, principle of mapping supports the two primary principles by delineating the relationship between a component in the conceptual model and the real world (Norman, 1988).

It is this manifestation of this principle, along with the overall conceptual model, that often make the affordances of one object (or online environment) more desirable than the affordance of a similar object or environment (Norman, 1988; Williams, 2010). As it pertains to this study, a key item of interest is examining how the conceptual models of communication invoked in Elluminate (now known as Blackboard Collaborate: http: / / www.blackboard.com/Platforms/Collaborate/Overview.aspx) and Second Life (http: / / secondlife.com/) map back to the process illustrated in Figure 1. Both employ unique forms of establishing user presence (Minsky, 1980) in order to facilitate the communication and information processing exchange. Elluminate employs a 
conceptual model that is relatively abstract in its establishing of a user's presence; it does so simply by having a user's name listed on the conference session's participant list. As users communicate, their name appears next to their typed statements within a text chat frame in the Elluminate screen. Conversely, Second Life employs a conceptual model that affords a more visual human presence by providing avatars for each user to serve as their virtual presence as they communicate and interact within the virtual world.

In terms of the common affordances associated with their respective models, both environments used in this study incorporate technologies supporting synchronous communication, e.g., text chat, emotes, and audio conferencing. For the purpose of establishing baseline measures in this exploratory study, only visual communications were used, e.g., text chat and emotes. Doing so enabled the research to focus on how the visual affordances of each environment mapped to the communication process. It also precluded the study from violating Norman's second principle, "make things visible" (Norman, 1988).

\section{Methods}

\section{Research questions}

This study used a mixed method design to investigate how the affordances (e.g., visual cues) from avatars and emoticons influenced learners' abilities to follow and understand synchronous, multi-person discussions. The authors also investigated whether certain learning styles would benefit more than others from these affordances. In completing this study, the authors sought to answer the following research questions:

1. Is there a difference in learners' ability to follow the flow of conversation in an avatar-based collaborative environment versus a non-avatar-based collaborative environment?

2. Is there a difference in learners' information retention levels in an avatar-based collaborative environment versus a non-avatar-based collaborative environment?

3. To what degree, if any, is there a relationship between learning styles and performances in collaborative environments regarding (a) information retention levels and (b) the ability to follow the flow of small group discussions?

\section{Significance of research}

The results of this study may benefit three distinct groups of individuals: (i) those involved with online distance learning; (ii) creators of $2 \mathrm{D}$ and $3 \mathrm{D}$ collaborative environments; and (iii) researchers engaged in investigations in computer-mediated communications. Albeit an exploratory work, this research aids instructional designers, program managers, and teachers in recognising possible affordances and limitations of the $2 \mathrm{D}$ and $3 \mathrm{D}$ environments related to small group discussions. To a lesser degree the second and third groups (i.e., environment creators and communication researchers, respectively) benefit from this research by gaining insights into end user preferences, perceptions related to these environments, and how this knowledge can inform their future work. 


\section{Restrictions and limitations}

As with all research, inherent limitations exist within this study. Given this is an exploratory study seeking to establish baseline measures for specific elements (e.g., text-based communications) within 2D and 3D collaborative environments, several additional limitations were imposed by the researchers in order to restrict the number of mitigating factors at play within the selected environments. The first of the three restrictions was to limit dialogues to text-based communications only. This was done to focus on the visual affordances of these environments. Later studies will undertake alternative communication modes, e.g., audio. The second restriction was to limit research to (a) following and (b) recalling conversational dialogues and not to include a third, highly variable, factor of participation. In doing so, researchers were able to eliminate extraneous variables (e.g., user typing skills, user skill levels within both environments, personality traits - shy versus overt behaviours, etc.). The third limitation is due to the relatively unexplored nature of virtual worlds. While the volume of research related to virtual worlds is growing, it is still a comparatively unexplored domain. As such, there are few baseline measures or established data sets upon which to build more advanced research. Therefore studies, such as this one, must begin at the most basic of levels, such as perceiving and interpreting information for these environments before building up to conduct more complex studies, for example multimodal communication, participatory discussions, etc. Having stated these limitations, there is still unique and compelling insights associated with this line of inquiry that can be drawn to inform future research and advance the field.

\section{Data collection}

This mixed method study recruited participants for a 30 minute session that included viewing of recorded online discussions, completion of a demographic information questionnaire, and submission of a learning styles assessment. It should be noted that recorded online discussions were produced using Second Life, version 2 of Linden Lab's viewer, and Elluminate, version 9. Participants were drawn from the University of South Florida through the distribution of flyers and engaging of students individually on campus. The students were enrolled in undergraduate and graduate programs. No one under 18 years of age was included.

Data gathering began with participants being alternately assigned to Group A or B based upon the random order in which they arrived for the study session. Next, the researchers asked the students to view videos of multiperson discussions in two different collaborative environments, Elluminate and Second Life. Learners were asked to answer a series of short questions immediately after viewing each video. Videos of discussions were used (a) to minimise the aforementioned 'noise' for users who might be distracted by interface and navigation controls, and (b) to ensure identical presentation of content to all users. The sequence of the videos was offset to minimise the potential influence of order effect on participant responses. Following the viewing of all the videos, learners completed a Visual/Auditory/Kinesthetic (VAK) learning styles assessment.

For the first video, Group A members viewed a five person discussion in Second Life while Group B members viewed a five person discussion in Elluminate. Both groups viewed conversations with identical dialogues and the personas in the videos also were identically named. After the first video, the participants answered a series of short questions about content (i.e., 'what was said') and about following (i.e., 'who said 
$\left.i^{\prime}\right)$. For the second video, the sequence switched so that Group A viewed a five person discussion in Elluminate while Group B viewed a five person discussion in Second Life. Again, both groups viewed conversations with identical dialogues and personas. The discussion in video 2 was a continuation of the discussion in video 1 . The participants again answered a series of short questions regarding content and following after watching the second video. When finished answering the questions after video 2 , the participants completed the VAK learning styles assessment instrument.

Three instruments were used in this study: (i) demographics questionnaire, (ii) video comprehension questionnaire, and (iii) the VAK learning styles survey. The demographics questionnaire and the video comprehension questionnaire were developed by the authors and reviewed by experts for content validity. Questions that were identified as being ambiguous were rewritten to ensure clarity and balance between the video simulations for both Elluminate and Second Life.

The VAK learning styles survey (Chislett \& Chapman, 2005) consists of 13 items with three possible answers per question - one answer indicates an auditory learning style, another answer indicates a visual learning style, and a third answer points towards a kinesthetic learning style. The VAK instrument's scoring matrix was used to determine the learning style of each participant. This dominant style defines the preferred way for a person to learn new information by filtering what is to be learned (Rourke, Ahmad, Collins, Hayman-Abello, Hayman-Abello \& Warriner, 2002). Although the efficacy of learning styles is still the subject of on-going research (Coffield, Moseley, Hall \& Ecclestone, 2004; Curry, 1990; Hickcox, 2008; Litzinger, Lee, Wise \& Felder, 2007; Moran, 1991; Slack \& Norwich, 2007), this construct was incorporated into the study in order to examine possible connections between learning styles and the affordances associated with Elluminate and Second Life in terms of (i) the retention of information, and (ii) the ability to better follow the flow of a synchronous conversation within the different collaborative environments.

\section{Results}

To answer each of the research questions, scores were calculated for the accuracy of students' retention based upon the answers given in their questionnaires. Retention accuracy scores were calculated for three categories: (a) Content: accurately recalling specific facts or statements made during the conversation; (b) Follow: ability to follow the conversation and properly identify who said what; and (c) Overall: total points from both Content and Follow.

In addition to quantitative measures, a theme analysis of the video comprehensive questionnaire was conducted in order to identify and quantify unique and recurrent themes among the responses from the study's participants. Themes were identified along two constructs (Owen, 1984) - "repetition" of terms (i.e., the exact same word or phrase being used repeatedly), and "recurrence" (i.e., the same meaning was implied although the exact wording may have varied slightly). To guard against potential bias, content from randomly selected questionnaire items was analysed by multiple people and discrepancies between theme definitions and counts were reconciled.

\section{Participant demographics}

A total of 42 participants responded to the survey and were randomly assigned to either Group A or Group B. Group A consisted of 21 participants including 12 females 
and 9 males with a mean age of 32. Group B consisted of 17 females and 4 males with a mean age of 38. Utilising the VAK learning styles assessment, the half of the participants registered as visual learners and the rest of the participants were split relatively equally across the visual, kinesthetic, and multimodal preferences (see Table 1 below). With the exception of Group B having a large ratio of females to males (17:4), the groups were comparable in terms of age and learning style preferences.

Table 1: Demographic data for study participants

\begin{tabular}{|c|c|c|c|c|c|c|c|c|}
\hline \multirow{2}{*}{ Group } & \multirow{2}{*}{ Size } & \multicolumn{2}{|c|}{ Gender } & \multirow{2}{*}{$\begin{array}{c}\text { Mean } \\
\text { age }\end{array}$} & \multicolumn{4}{|c|}{ VAK } \\
\hline & & Male & Female & & V & $\mathrm{A}$ & $\mathrm{K}$ & Multi \\
\hline A & 21 & 9 & 12 & 32 & 11 & 2 & 5 & 3 \\
\hline B & 21 & 4 & 17 & 38 & 11 & 4 & 4 & 2 \\
\hline
\end{tabular}

\section{Research question 1: Learners' ability to follow the flow of conversation in an avatar-based collaborative environment versus a non-avatar-based collaborative environment}

Participants from both groups, A and B, performed slightly better when following conversations in the avatar-based environment, Second Life, versus Elluminate. For this research question, performances were measured in terms of recalling information from the conversations and correctly answering questions about the flow of the conversation. Participants in Group A were able to accurately follow conversations in Second Life 10\% better than in Elluminate (59\% versus 49\%) and students in Group B performed 13\% better in Second Life than they did in Elluminate (56\% versus 43\%), see Table 3. In both cases, the difference between the means was meaningful, albeit statistically not significant.

It should be noted, the pattern of producing results that are generally consistent and interesting, but fall shy of being statistically significant (as seen in the tables above), is repeated throughout this study's findings. As a result, when examining individual assessments, e.g., performance scores for following conversational flow, few statistically significant claims arise. However, when considering the repeating patterns in the quantitative and qualitative findings, overall trends emerge that lend support to the conclusions drawn at the end of this article.

An analysis of participants' statements showed the majority of the student comments favoured the 3D avatar environment. Prominent themes emerged in areas of being able to follow conversations, identifying speakers, making connections with the people speaking, decreasing distractions, a sense of more realism, and a better organisation and interest in the information in the avatar environment (Table 2).

It is of interest that seven participants, which amounts to approximately one seventh of the total respondents, commented that the avatar environment was more realistic than the emoticon and text environment. The same portion also commented that there was "an increased sense of connection" with the avatars. Approximately one fourth of the study participants found that the avatar environment held their attention more and was an environment that made it easier to identify the speaker in a group conversation, follow a conversation, and retain the information. 
Table 2: Themes associated with following discussions in Second Life and Elluminate

\begin{tabular}{|l|c|l|}
\hline \multicolumn{1}{|c|}{ Themes } & $\begin{array}{l}\text { Number of } \\
\text { occurrences }\end{array}$ & \multicolumn{1}{c|}{$\begin{array}{c}\text { Samples statements from participants } \\
\text { (SL is Second Life, E is Elluminate) }\end{array}$} \\
\hline $\begin{array}{l}\text { Attention } \\
\text { Interest/wandering }\end{array}$ & 13 & $\begin{array}{l}\text { I wasn't focusing on the flashing icons (E) } \\
\text { I found myself staring... rather than listening (E) } \\
\text { I can watch the screen (SL) } \\
\text { I tended to wander (E) }\end{array}$ \\
\hline $\begin{array}{l}\text { Identification of } \\
\text { speaker }\end{array}$ & 13 & $\begin{array}{l}\text { Easier to discern who the speaker was (SL) } \\
\text { Better highlights of persons speaking (SL) }\end{array}$ \\
\hline $\begin{array}{l}\text { Following } \\
\text { conversation }\end{array}$ & 7 & $\begin{array}{l}\text { It was easier to follow the conversation (SL) } \\
\text { Visuals much easier to remember and follow (SL) }\end{array}$ \\
\hline Realism & $\begin{array}{l}\text { The people made it more lively, almost realistic (SL) } \\
\text { It was like a real group discussion (SL) } \\
\text { Once I got over the 'creepiness' of SL I think discussions are } \\
\text { more realistic in SL }\end{array}$ \\
\hline $\begin{array}{l}\text { Connections with } \\
\text { people }\end{array}$ & 7 & $\begin{array}{l}\text { Creative there is a sense of connectedness (SL) } \\
\text { Could relate to the characters seeing them as avatars (SL) }\end{array}$ \\
\hline Visual preferences & 6 & I'm visual... SL helped organize the conversation \\
\hline
\end{tabular}

Five of the participants, in unsolicited comments after completion of the questionnaire, stated emphatically that "Second Life was easier to follow" what was going on in the group discussion. Several comments made the point that certain learners find it very important to be able to associate an idea with a person's (or in this case, an avatar's) face.

\section{Research question 2: Learners' content retention levels in an avatar-based collaborative environment versus a non-avatar-based collaborative environment}

As with question one, students in Group A performed nearly $10 \%$ better in accurately answering questions related to recalling content from conversations in Second Life as compared to Elluminate (68\% versus 59\%). However, in the one exception to the overall patterns found in this study's findings, participants in Group B performed slightly better at recalling content from the Elluminate conversation (59\% versus 57\%), see Table 3. This is possibly due to the larger percentage of audio-preference learners in Group B than were found in Group A ( see Research question 3 below).

Table 3: Mean scores and performance results for Group A and Group B participants

\begin{tabular}{|c|c|c|c|c|c|c|c|c|c|}
\hline \multirow{2}{*}{ Group } & \multicolumn{3}{|c|}{$\begin{array}{c}\text { SL mean scores } \\
\% \text { correct }\end{array}$} & \multicolumn{3}{c|}{$\begin{array}{c}\text { Elluminate mean scores } \\
\text { \% correct }\end{array}$} & \multicolumn{2}{c|}{$\begin{array}{c}\text { Results: Higher } \\
\text { performance }\end{array}$} \\
\cline { 2 - 10 } & Content & Follow & Overall & Content & Follow & Overall & Content & Follow & Overall \\
\hline A & $68 \%$ & $59 \%$ & $64 \%$ & $59 \%$ & $49 \%$ & $54 \%$ & SL & SL & SL \\
\hline B & $57 \%$ & $56 \%$ & $56 \%$ & $59 \%$ & $43 \%$ & $51 \%$ & E & SL & SL \\
\hline
\end{tabular}

Two prominent trends were identified among the comments from study participants which may explain part of the strong showing by the 3D environment. Nearly $30 \%$ of the students commented that 'having a face to go along with the information' made recall of the information easier. They could remember who said what better than trying to associate the same ideas to the more abstract representations of user presences (i.e., user names on a list) that are typically utilised in 2D environments. Similarly nearly $20 \%$ of the students also stated that trying to keep track of the changing emoticons in the $2 \mathrm{D}$ environment while trying to following the flow of the 
conversation was cognitively taxing. Second Life, with its realistic presentation of users and their conversation was less distracting and easier to follow.

To investigate the degree to which Second Life typically outperformed Elluminate, paired t-tests were conducted 'within group' (e.g., Group A's performance related to the Second Life video versus its performance for the Elluminate video) and 'between' groups (e.g., video 1: Group A Second Life vs. Group B Elluminate; video 2 Group A Elluminate vs. Group B Second Life).

\section{Within group}

Students in both groups generated higher scores with the Second Life conversation in all categories, save one. Group B performed slightly better recalling Content using Elluminate, although the difference was so small $(\mathrm{t}=0.162, \mathrm{p}=0.872)$ that one could reasonably argue that the performances were basically equal, see Table 4 . In the other categories students performed better with Second Life discussions; however, none of the differences were large enough to be statistically significant.

Table 4: Comparisons of content recall and discussion following performances within groups

\begin{tabular}{|c|c|c|c|c|c|c|}
\hline Group & Condition & Result & t-score & Crit t-score & p-value & Significant \\
\hline A & Content & SL & 0.938 & 1.683 & 0.354 & No \\
\hline A & Follow & SL & 0.886 & 1.683 & 0.381 & No \\
\hline A & Overall & SL & 1.038 & 1.683 & 0.305 & No \\
\hline B & Content & E & 0.162 & 1.683 & 0.872 & No \\
\hline B & Follow & SL & 1.191 & 1.683 & 0.241 & No \\
\hline B & Overall & SL & 0.609 & 1.683 & 0.546 & No \\
\hline Combined & Content & SL & 0.570 & 1.666 & 0.570 & No \\
\hline Combined & Follow & SL & 1.470 & 1.666 & 0.147 & No \\
\hline Combined & Overall & SL & 1.172 & 1.666 & 0.245 & No \\
\hline
\end{tabular}

$\mathrm{df}=41$ for groups $\mathrm{A}$ and $\mathrm{B} ; \mathrm{df}=83$ for Combined

Between group

Comparisons between the groups showed the same trends as within group comparisons, in that performances associated with the Second Life discussions were higher than Elluminate, with one exception. Video 2's Content recall condition (i.e., Group A Elluminate, Group B Second Life), when Elluminate performed higher (Group A (E) $59 \%$ vs. Group B (SL) 57\%), see Table 5. However, in the between group comparison, no scores were statistically significant with $\mathrm{p}<0.05$, though video 1 scores for Follow and Overall had comparatively low p-values.

Table 5: Comparisons of content recall and discussion following performances between groups

\begin{tabular}{|l|c|c|c|c|c|c|c|}
\hline & Group & Condition & Result & t-score & Crit t-score & p-value & Significant \\
\hline Video 1 & A SL v B E & Content & SL & 1.056 & 1.683 & 0.297 & No \\
\cline { 2 - 7 } & A SL v B E & Follow & SL & 1.432 & 1.683 & 0.160 & No \\
\cline { 2 - 7 } & A SL v B E & Overall & SL & 1.425 & 1.683 & 0.162 & No \\
\hline Video 2 & A E v B SL & Content & E & 0.150 & 1.683 & 0.882 & No \\
\cline { 2 - 8 } & A E v B SL & Follow & SL & 0.618 & 1.666 & 0.539 & No \\
\cline { 2 - 7 } & A E v B SL & Overall & SL & 0.255 & 1.666 & 0.800 & No \\
\hline
\end{tabular}




\section{Research question 3: Relationship between learning styles and performances in collaborative environments regarding (a) retention levels and (b) the ability to follow conversations}

Performances related to Content recall and Following conversation flow were segregated based on the participants' VAK category. The only statistically significant result in relation to Research question 3 came from students in Group B who were identified as auditory learners. They performed significantly better in Content recall with the Elluminate discussion than with Second Life, t-score of 2.236 (critical score $1.769, \mathrm{p}<0.05$ ). While this does stand in contrast to most of the other findings in this study, it does align with a few other elements. The Content measure of Group B showed slightly higher performance with Elluminate in the within group comparison. Also, Group A had a higher performance with Elluminate in the Content section during video 2 in the between group comparison. Outside of the Group B's auditory learners performance related to Content, all other groups, learning styles, and performance categories favoured Second Life, albeit without statistical significance.

\section{Discussion}

Although there was only one statistically significant finding generated by the raw data, there were meaningful trends among both the quantitative and qualitative data to warrant serious considerations in answering each of the three research questions.

When addressing the first question regarding differences between learners' ability to follow the flow of conversations in the $2 \mathrm{D}$ and $3 \mathrm{D}$ environments, the majority of the students participating in the study found it easier to follow conversations in Second Life versus Elluminate. With the Second Life environment, students stated that "I wasn't focusing on the flashing icons [of Elluminate]," "[it was] easier to discern who the speaker was," and "visuals much easier to remember and follow." As a result, learners in both treatment groups scored an average of $10 \%$ to $13 \%$ higher in their ability to follow a conversation in Second Life. This easing of the cognitive burden may be attributable to a better conceptual model of communication and greater affordances for information processing associated with Second Life than with Elluminate. By establishing a greater sense of presence (Minsky, 1980), the conceptual model (Norman, 1988) underlying Second Life better emulates the natural information processing and communication patterns of learners, thereby giving a slightly enhanced performance level in Second Life.

This has several potential implications for online instruction. The increased ability to follow conversations can potentially contribute to learners' abilities to (a) internalise new content and ideas presented as part of lessons carried out in a 3D environment, (b) participate and become engaged in synchronous discussions held online, and (c) develop a sense of community and belonging as they are able to follow and learn from conversations with their peers.

For Research question 2, differences in learners' content retention levels, learners again generally performed as well, if not better, in the 3D avatar-based environment than the 2D environment. Learners' ability to better organise information and more easily associate a face/person with an idea in the $3 \mathrm{D}$ environment as well as the large percentage of visual learners appears to have contributed to $10 \%$ to $13 \%$ improvement in performance associated with the Second Life discussions versus the Elluminate 
discussions. The one exception to this trend, where Group B performed slightly better (2\%) at recalling Content in the Elluminate environment, could be due to the slightly larger percentage of auditory learners in Group B versus Group A (see Table 1).

As with Research question 1, it appears that Second Life's ability to better map (Norman, 1988) or emulate real world communication practices into its virtual space may aid learners in coding and recalling information (Potter, 2004). The implications for online learning are similar to those discussed in Research question 1 - better coding of content and a possible impact on engagement and sense of community.

Finally, for Research question 3, the relationship between learning styles and learners' ability to follow conversations and retain content from synchronous discussions, audio-oriented learners in one group did perform significantly better in their ability to recall content presented in an Elluminate discussion. However, for all other groups, learning styles, and performance categories, learners posted stronger results and stated stronger preferences for conversations held in Second Life. The study's relatively small sample size, $n=42$, leaves the door open to questions regarding definitive correlations between learning styles and performances related to following and recalling discussions in collaborative environments. With this in mind, additional studies with larger sample sizes should be conducted.

Until that point in time, however, the recurring trends in performance and learner preferences warrant further investigation. There appears to be meaningful implications for organising and conducting synchronous instructional sessions in avatar-based 3D environments. The better conceptual model underlying virtual world discussions, as manifested by increased user presence, appears to contribute to an increased sense of realism and greater ease in communication. Learners feel a stronger sense of connectedness and engagement.

While both Elluminate and Second Life hold good potentials for hosting online discussions, each has its strengths and limitations. Our findings indicate that due to its limited visual affordances, Elluminate does not facilitate the establishing of an online user presence as well as Second Life. Subsequently, it does not emulate the traditional communication process for small scale discussion very well (see Figure 1). Because of the visual affordances of Second Life, users can identify speakers better, focus and organise information better, and feel a stronger sense of connection with others than with Elluminate. The end result is that learners involved with small scale discussions in Second Life typically can follow the conversation better and recall the information better. For practitioners of online instruction, these insights have meaningful implications by aiding them in the selection of appropriate collaborative environments for hosting their class discussions. For small group discussions, 3D environments such as Second Life appear to have strong advantages over using 2D, non-avatar-based, environments. Finally, learning styles appear to have limited association with communication channels within the environments. Visual learners definitely preferred the highly visual space of Second Life; whereas auditory learners performed well in recalling information from the less visual and, therefore more audio-dominant, Elluminate environment. In those cases where online instructions know the learning preferences of their students, this information again can help instructors in better selecting appropriate environments fitting their students' learning styles. 
For all of its potential benefits (e.g., better communication model, free cost, crossplatform availability, etc), Second Life does possess several barriers to adoption. Second Life requires a greater learning curve to become a proficient user. It also requires a greater amount of network bandwidth and due to the open nature of its content creation there are segments of the virtual world that are not appropriate for children and young adults. These are concerns warranting meaningful reflection before actively adopting Second Life based findings in this and other exploratory studies.

As with all aspects of computer assisted learning, additional research is needed to validate the trends found in this study and extend the research to alternative configurations (e.g., large group discussions, auditory and multimodal discussions, long discussion versus short discussions, etc.). One of the first studies could be to extend the nature of participants interactions in the discussion beyond the controlled observation-driven format used in this study. It would be interesting and important to note how learner performances may or may not change when they are required to observe and follow conversations, as well as engage and interact in them. Until that time, the current research provides some insights into the selection of collaborative environments for use in facilitating learning with small groups of learners.

\section{References}

Berge, Z. L. (2002). Active, interactive, and reflective elearning. Quarterly Review of Distance Education, 3(2), 181-190.

Chislett, V. \& Chapman, A. (2005). Free VAK visual auditory kinesthetic learning styles test questionnaire. http: / / www.businessballs.com/vaklearningstylestest.htm [viewed 23 Mar 2009]

Coffield, F., Moseley, D., Hall, E. \& Ecclestone, K. (2004). Should we be using learning styles?: What research has to say to practice. London: Learning and Skills Research Centre. http:/ / www.lsnlearning.org.uk/search/Resource-32186.aspx [viewed 14 May 2010]

Croft, R. S. (2004). Communication theory. [viewed 30 Apr 2010 at http:/ / www.cuvo.com/CroftCommunication.pdf; not found 29 Oct 2012, see http:/ / pdfworld.net / pdf/ 428785/Communication-Theory-Richard-S.-Croft-pdf.php]

Curry, L. (1990). One critique of the research on learning styles. Educational Leadership, 48, 50-56. [verified 29 Oct 2012] http:/ / 12.4.125.3/ ASCD/pdf/journals/ed_lead/el_199010_curry.pdf

Dawson, C (2011). Blackboard Collaborate formally launched at BBWorld 2011. ZDNet, 11 July. http: / / www.zdnet.com/blog/ education/ blackboard-collaborate-formally-launched-atbbworld-2011/4640

Dede, C. (2005). Planning for neomillennial learning styles: Implications for investments in technology and faculty. In D. G. Oblinger \& J. L. Oblinger (Eds.), Educating the Net Generation. http:// www.educause.edu/educatingthenetgen/ [viewed 18 May 2010]

Garrison, D. R. \& Anderson, T. (2003). E-learning in the 21st century: A framework for research and practice. London, UK: Routledge Farmer.

Gibson, J. J. (1977). The theory of affordances. In R. Shaw \& J. Bransford (Eds.), Perceiving, acting, and knowing. Hillsdale, NJ: Lawrence Erlbaum Associates.

Gunawardena, C. N. (1995). Social presence theory and implications for interaction and collaborative learning in computer conferences. International Journal of Educational Telecommunications, 1(2), 147-166. http:/ / www.editlib.org/p/15156 
Hickcox, L. K. (2008). Learning styles: A review of the inventories - 1960s-2000s and the question of their actual uses inside and outside of the classroom. In E. P. Velliotis (Ed.), Classroom culture and dynamics. New York: Nova Science Publishers.

International Society for Presence Research (2000). The concept of presence: Explication statement. http: / / ispr.info/about-presence-2/ about-presence/ [viewed 30 Apr 2010]

Lasswell, H. (1948). The structure and function of communication in society. In L. Bryson (Ed.), The communication of ideas. New York: Harper.

Lee, D. (1993). Developing effective communications. [viewed 30 Apr 2010, verified 29 Oct 2012] http: / / extension.missouri.edu/p/CM109

Litzinger, T. A., Lee, S. H., Wise, J. C. \& Felder, R. M. (2007). A psychometric study of the index of learning styles. Journal of Engineering Education, 96(4), 309-319. [verified 29 Oct 2012] http:/ / www4.ncsu.edu/unity/lockers/users/f/felder/public/ILSdir/ILS_Validation(JEE-2007).pdf

McLuhan, M. (1964). Understanding media: The extensions of man. Cambridge, Massachusetts: The MIT Press.

McQuail, D. (1994). Mass communication theory. London: Sage Publications Ltd.

Minsky, M. (1980). Telepresence. OMNI Magazine, June 1980, 45-51. [verified 29 Oct 2012] http: / / web.media.mit.edu/ minsky/ papers/Telepresence.html

Moran, A. (1991). What can learning styles research learn from cognitive psychology? Educational Psychology, 11(3\&4), 239-245. http:/ / dx.doi.org/10.1080/0144341910110303

Muirhead, B. (1999). Attitudes toward interactivity in a graduate distance education program: A qualitative analysis. Doctoral dissertation, Capella University.

Narula, U. (2006). Communication models. New Delhi: Atlantic Publishers.

Norman, D. A. (1988). The psychology of everyday things. New York: Basic Books, Inc.

Northrup, P. (2009). Online learners preferences for interaction. In A. Orellana, T. L. Hudgins \& M. Simonson (Eds.), The perfect online course: Best practices for designing and teaching. Scottsdale, AZ: Information Age Publishing.

Ott, R. (2001). Faculty perspective... why online? In I. Lach (Ed.), Illinois Virtual Campus Newsletter, Winter 2001. http:// www.ivc.uillinois.edu/pubs/newsletter/ winter2001.pdf [viewed 16 Apr 2010; not found 29 Oct 2012]

Owen, W. F. (1984). Interpretive themes in relational communication. Quarterly Journal of Speech, 70, 274-287. http:/ / dx.doi.org/10.1080/00335638409383697

Palloff, R. M. \& Pratt, K. (2003). Virtual student: A profile and guide to working with online learners. San Francisco: Jossey-Bass.

Potter, J. (2004). Theory of media literacy: A cognitive approach. Thousand Oaks, CA: Sage.

Rourke, B., Ahmad, S., Collins, D., Hayman-Abello, B., Hayman-Abello, S. \& Warriner, E. (2002). Child clinical/pediatric neuropsychology: some recent advances. Annual Review of Psychology, 53, 309-339. http:/ / dx.doi.org/ 10.1146/ annurev.psych.53.100901.135204

Slack, N. \& Norwich, B. (2007). Evaluating the reliability and validity of a learning styles inventory: A classroom-based study. Educational Research, 49(1), 51-63. http: / / dx.doi.org/10.1080/00131880701200765 
Shannon, C. E. \& Weaver, W. (1949). A mathematical model of communication. Urbana, IL: University of Illinois Press.

Su, B., Bonk, C. J., Magjuka, R. J., Liu, X. \& Lee, S. (2005). The importance of interaction in webbased education: A program-level case study of online MBA courses. Journal of Interactive Online Learning, 4(1), 1-19. http: / / www.ncolr.org/jiol/issues/pdf/4.1.1.pdf

Swan, K. (2001). Virtual interaction: Design factors affecting student satisfaction and perceived learning in asynchronous online courses. Distance Education, 22(2), 306-331. http: / / dx.doi.org/10.1080/0158791010220208

Wang, Z. (2008). Another dimension of web-based learning: Psychological bestirring. In F. Li, J. Zhao, T. K. Shih, R. Lau, Q. Li \& D. McLeod (Eds.), Advances in web-based learning - ICWL 2008, pp. 390-397. Berlin: Springer-Verlag.

Wells, G. (1986). The meaning makers: Children learning language and using language to learn. Portsmouth, NH: Heinemann.

Williams, D. (2010). The mapping principle, and a research framework for virtual worlds. Communication Theory, 20(4), 451-470. http: / / dx.doi.org/10.1111/j.1468-2885.2010.01371.x

Authors: Associate Professor Steve Downey PhD (corresponding author) Department of Curriculum, Leadership, and Technology

Valdosta State University, 1500 N. Patterson, Valdosta, GA 31698, USA

Email: sedowney@valdosta.edu Web: http:/ / ww2.valdosta.edu/coe/clt /

Dr Steve Downey was formerly an Assistant Professor of Instructional Technology in the College of Education, University of South Florida, where he taught graduate courses on virtual worlds and media production, and led the Worlds of Education initiative, http:/ / www.coedu.usf.edu/we/

Jill Mohler, Joan Morris, and Rene Sanchez are graduates of the University of South Florida's Master of Instructional Technology program who conducted virtual world research while studying with Dr Downey.

Please cite as: Downey, S., Mohler, J., Morris, J. \& Sanchez, R. (2012). Learner perceptions and recall of small group discussions within 2D and 3D collaborative environments. Australasian Journal of Educational Technology, 28(8), 1405-1419. http:/ / www.ascilite.org.au/ajet/ajet28/downey.html 